\title{
Lipoprotein lipase: regulation and role in lipoprotein metabolism
}

\author{
BY T. OLIVECRONA, M. HULTIN, M. BERGÖ AND G. OLIVECRONA
}

Department of Medical Biochemistry and Biophysics, Umeå University, S-90187 Umeå, Sweden

Humans and animals deficient in lipoprotein lipase (EC 3.1.1.34; LPL) develop a massive hypertriacylglycerolaemia (Brunzell, 1995). Hence, LPL-mediated hydrolysis of lipoprotein-triacylglycerols is a necessary step in lipoprotein metabolism. The reaction occurs at 'binding-lipolysis' sites at the vascular endothelium (Olivecrona \& Olivecrona, 1995). Here the enzyme is anchored by interaction with heparan sulfate chains from proteoglycans in the endothelial cell membrane. The reaction creates a high local concentration of fatty acids and these fatty acids can go two ways: immediate metabolism in subjacent tissue cells or transport into the general circulation in complex with albumin.

There is evidence that in adipose tissue the uptake of fatty acids from chylomicrons correlates with the local LPL activity (Cryer et al. 1976). This has led to the concept that LPL activity determines where fatty acids from triacylglycerol-rich lipoproteins are metabolized. Recent studies on mice that express LPL in only one tissue show, however, that lipoprotein metabolism is largely normal (Levak-Frank et al. 1995). The implication is that the fatty acids released by LPL can be transported in the blood to other sites for metabolism. This is in line with data and speculations from Frayn's group (Samra et al. 1996). They have shown that adipose tissue always releases fatty acids (FFA) but the source differs. In the fasted state the fatty acids are derived from lipolysis of stored triacylglycerols but in the fed state most of them are derived from lipolysis of lipoproteintriacylglycerols by LPL.

To study how fatty acids from chylomicrons partition between immediate uptake and recirculation in plasma FFA we have studied the metabolism of labelled chylomicrons in rats, and have analysed the results by compartmental modelling (Hultin et al. 1996). We gave the donor rats oleic acid, which becomes incorporated in the chylomicron triacylglycerols, and retinol, which appears as retinyl esters in the chylomicrons and, hence, provides a label for the core material that remains with the particle after lipolysis.

The disappearance curves for both labels extrapolated to a volume that appeared to be larger than the blood volume. To study this more directly we injected ${ }^{51} \mathrm{Cr}$-labelled erythrocytes (RBC) together with the chylomicrons (Fig. 1). For RBC the distribution volume corresponded to about $5.6 \%$ of body weight in both fed and fasted rats. The distribution volumes for the chylomicron labels did not differ significantly between triacylglycerol or retinyl esters or between the nutritional states, but the distribution volumes were $10-25 \%$ larger for the chylomicron labels than for the RBC. As the two chylomicron labels behaved similarly, it is likely that it was the whole chylomicron that was distributed into the larger apparent volume. Some of this larger volume may be tissue spaces into which the chylomicrons have immediate access, such as the spaces of Disse in the liver. Some must represent dispersal of chylomicrons to endothelial binding-lipolysis sites. That dispersal occurs is not surprising. As lipolysis occurs at the endothelial sites, it is necessary that the chylomicrons remain at these sites for a significant time period (Olivecrona \& Olivecrona, 1995).

Harris \& Harris (1973) found that with increased amounts of injected chylomicrons, the distribution volume decreased. This suggests that the number of dispersal sites is limited and raises the question of whether one can subsequently change the dispersal. 
Fed rats

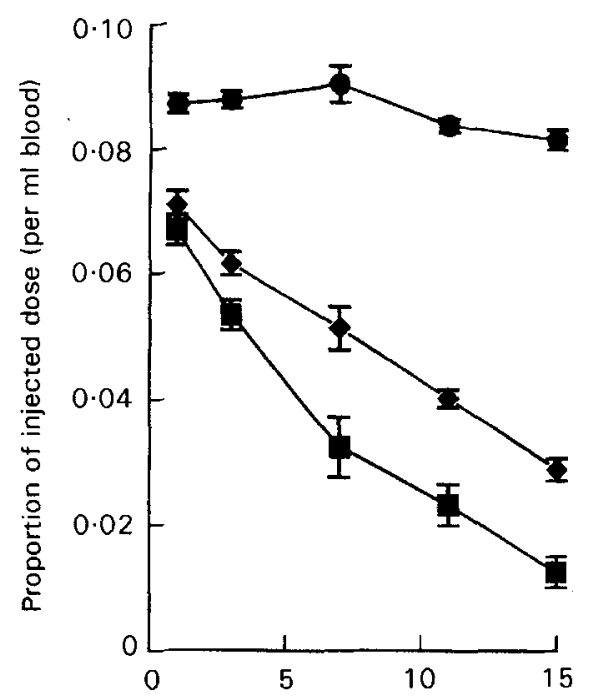

Fasted rats

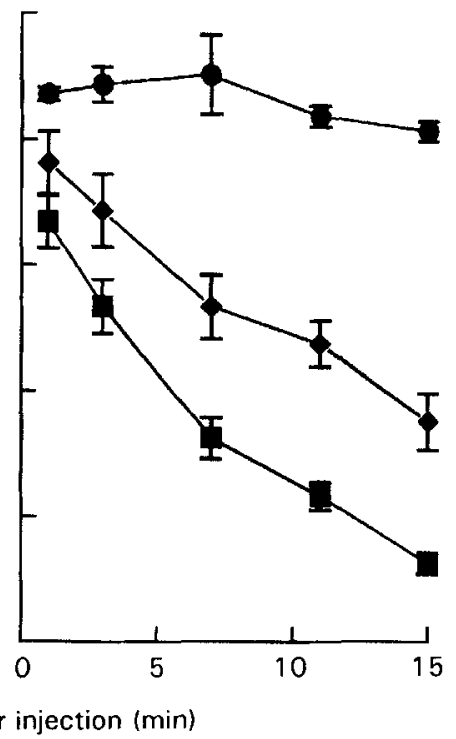

Fig. 1. Apparent distribution volumes of doubly-labelled chylomicrons compared with ${ }^{51} \mathrm{Cr}$-labelled erythrocytes $(\mathrm{RBC})$. The RBC $(\Theta)$ were injected $1 \mathrm{~min}$ before the chylomicrons ((core (retinyl ester) label $(\bullet)$, triacylglycerol label ( $\mathbf{\square})$ ) to anaesthetized fed and fasted rats. Serial blood samples were taken, and the radioactivities were determined. The results are expressed as the proportion of injected dose in $1 \mathrm{ml}$ blood. Values are means with their standard errors, represented by vertical bars, for five rats. (From Hultin et al. 1996.)

Evidence for this came from recent experiments by Karpe \& Hultin (1995). The main aim of their study was to explore the mechanism behind alimentary hyperlipaemia. For this purpose they created a triacylglycerol clamp model by infusion of a lipid emulsion to give a plasma triacylglycerol concentration of about $8 \mathrm{mmol} / \mathrm{l}$ in rats. This resulted in a progressive increase in apolipoprotein B-containing VLDL, suggesting that the emulsion particles displaced the endogenous lipoproteins from the lipolysis sites. To study this finding closer they injected doubly-labelled chylomicrons and found that clearance was indeed slowed down. We have re-analysed their data and found that the distribution volume for the injected chylomicrons decreased from about $125 \%$ to about $114 \%$ of the blood volume.

To model the partitioning of fatty acids from chylomicron lipolysis into plasma FFA it was necessary to be able to describe the behaviour of the FFA. Thus, we injected albuminbound labelled oleic acid together with chylomicrons to produce the correct background (Fig. 2). The disappearance curves for the labelled FFA could readily be simulated by an open two-compartment model. The central compartment represents FFA in blood, and tissue fatty acids that mix rapidly with the plasma FFA. The other compartment is a much larger pool of tissue lipids. In addition, there is a pathway for irreversible loss of material from the FFA pool, corresponding to oxidation. This model is not an attempt to understand how FFA are metabolized, it is a mathematical representation of how label that enters the plasma FFA behaves. We used this to model the behaviour of labelled fatty acids from hydrolysis of chylomicron triacylglycerols. 
(a)

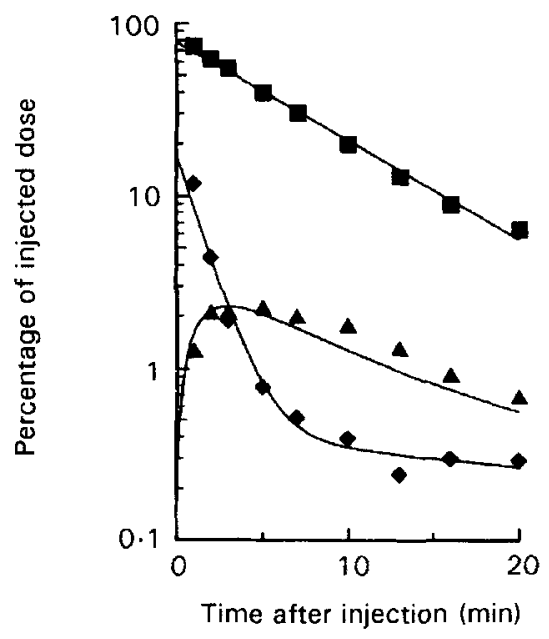

(c)

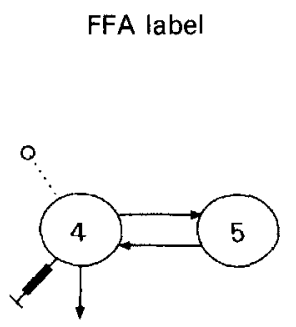

(b) Fasted

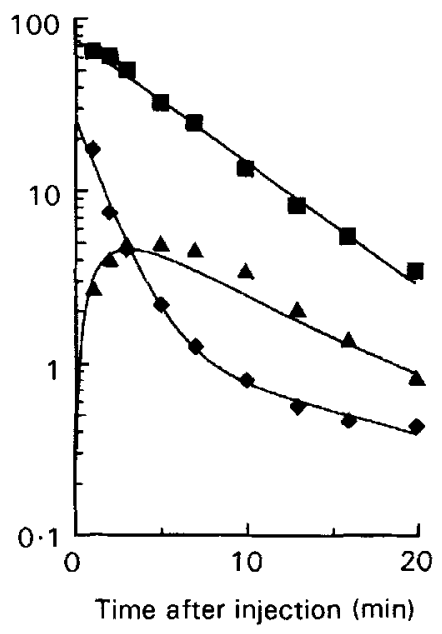

(d)

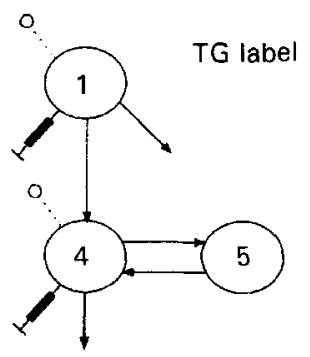

Fig. 2. Turnover of free fatty acids (FFA) and of chylomicron triacylglycerols (TG). ${ }^{14} \mathrm{C}$-labelled oleic acid complexed with albumin was mixed with $\left[{ }^{3} \mathrm{H}\right]$ oleic acid-labelled chylomicrons and injected into anaesthetized rats. The data were fitted to the models shown in (c) and (d). Compartment 1 represents chylomicron TG. There is a pathway out from this compartment that represents transfer of label to tissue metabolism without mixing with the FFA pool. Compartment 4 represents plasma FFA and fatty acids that mix almost instantaneously with the plasma FFA. Compartment 5 represents tissue lipids that exchange with the plasma FFA. There is a pathway out from compartment 4 which represents oxidation and storage in lipids that do not feed back to the plasma FFA. (a, b) Observed data for ${ }^{3} \mathrm{H}$-labelled FFA (A), ${ }^{3} \mathrm{H}$-labelled TG $(\boldsymbol{\square})$ and ${ }^{14} \mathrm{C}$-labelled FFA $(\bullet)$ in a representative fed and fasted rat respectively from groups of five rats. The curves are the derived fits from compartmental modelling. (From Hultin et al. 1996.)

In the following experiments we studied the fate of fatty acids from chylomicron triacylglycerols (Fig. 2). The simplest model would be that turnover is only by lipolysis and that all fatty acids mix with the FFA pool. This would give an open three-compartmental model with irreversible transfer of material from chylomicron triacylglycerols (compartment 1) into the FFA pool. The data for fasted rats fitted this simple model, but for fed rats this model resulted in calculated values for label in plasma FFA that were too high. Hence, it was necessary to allow some fatty acids to transfer from chylomicron triacylglycerols without mixing with the plasma FFA.

The implication is that somewhere in the body we should find more uptake of fatty acids from chylomicrons than from FFA and this should occur only, or mainly, in the fed state. We therefore compared the distribution of labelled oleic acid when given as the 
albumin complex and when present in chylomicron triacylglycerols (Hultin et al. 1996). In most tissues there was little or no difference. The main difference was in adipose tissue, and only in the fed state as previously observed by Bragdon \& Gordon (1958). Total uptake in adipose tissue accounted for $20-30 \%$ of the injected chylomicron label and this amount was about the same as the amount of fatty acids that apparently do not enter the plasma FFA.

These observations confirm the concept that a significant proportion of the fatty acids carried in chylomicrons is directly shunted into adipose tissue and is never available for metabolism by other tissues. This led us to re-examine the time-scale of changes in adipose tissue LPL and ask how the rapid changes are brought about (Bergö et al. 1996a). When rats were fasted, LPL activity dropped within $12 \mathrm{~h}$ to $25 \%$ of the fed control value and then decreased further, so that at $72 \mathrm{~h}$ it was about $10 \%$ of the control (Fig. 3). At $12 \mathrm{~h}$, LPL mRNA and mass had dropped to 80 and $60 \%$ of control values respectively, but then increased again so that at $24 \mathrm{~h}$ the values were 120 and $80 \%$ of control values respectively. These increases were statistically significant $(P<0.05)$ and occurred during the period when the rats normally had their most active feeding period (i.e. during the dark period). From these data it is clear that during the first day the changes in LPL activity are not due to changes in expression of the LPL gene but are due to changes in the ratio, active : inactive forms of the enzyme.

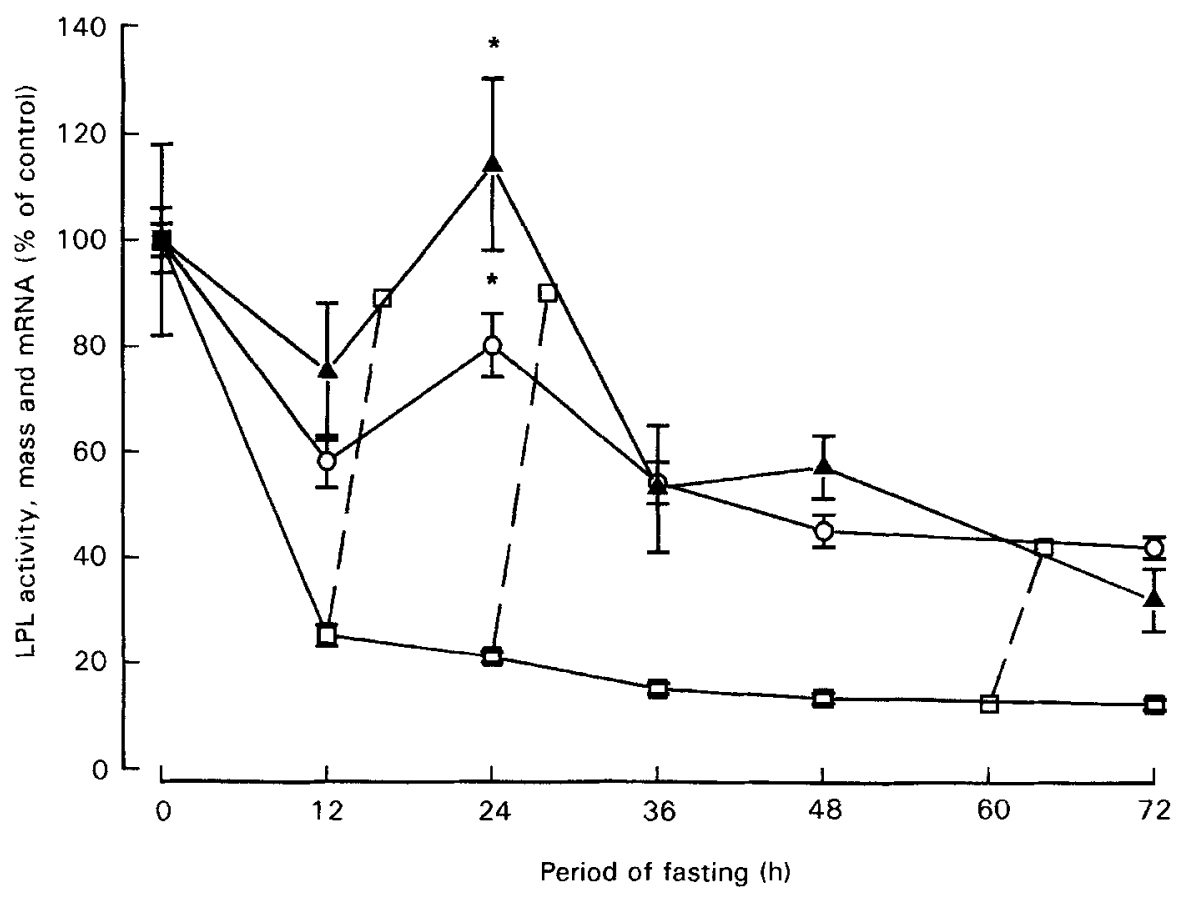

Fig. 3. Effect of fasting and re-feeding on adipose tissue lipoprotein lipase (EC 3.1.1.34; LPL). Groups of rats were fasted for the indicated time intervals (from 06.00 hours). Pieces of epididymal adipose tissue were taken for assay of LPL activity $(\square)$, LPL mass $(O)$ and LPL mRNA $(\mathbf{A})$. Values are means with their standard errors, represented by vertical bars for five rats. (-___ fasting value (Students $t$ test): ${ }^{*} P<0 \cdot 05$. (From Bergö et al. 1996a.) 
In the next experiment, rats were fasted for $24 \mathrm{~h}$ and then re-fed. The activity of LPL decreased to $20 \%$ of the fed control value during the fast, and increased rapidly on refeeding (Fig. 4). LPL mass dropped to 70-65\% of the fed control value during the fasting period and increased during re-feeding, reaching the level of the fed control after about $2 \mathrm{~h}$. The changes in the levels of mRNA were not statistically significant, but the levels tended to increase during fasting and decrease after re-feeding, i.e. if anything they changed in the opposite manner compared with LPL activity and mass. These data show that changes in LPL activity during short-term fasting occur primarily by a shift in the ratio, active: inactive forms of the enzyme. This allows the activity to be restored rather rapidly, which is reasonable from a physiological point of view; at any time during the day LPL activity can quickly be up-regulated to handle and store an ingested lipid load.

When fasting was continued beyond $24 \mathrm{~h}$, LPL mRNA and mass decreased. To study the effects of re-feeding after a longer fast we deprived the rats of food for $60 \mathrm{~h}$ (Bergö $\mathrm{et}$ al. 1996a). At this time the levels of LPL activity, mass and mRNA had decreased to 8, 22 and $50 \%$ of the fed control value respectively. On re-feeding, LPL activity rose in a biphasic manner. There was an initial rapid rise, which was mainly due to the return of the ratio LPL activity: LPL mass towards that in fed controls, and then a more gradual second phase in which the continued increase of LPL activity appeared to follow the slow return of mRNA levels towards those in fed controls. These data suggest that during longer periods of fasting the ability of adipose tissue LPL to increase in response to a meal becomes limited by a decreased mRNA level and, hence, a decreased ability to synthesize new enzyme molecules (Fig. 3).

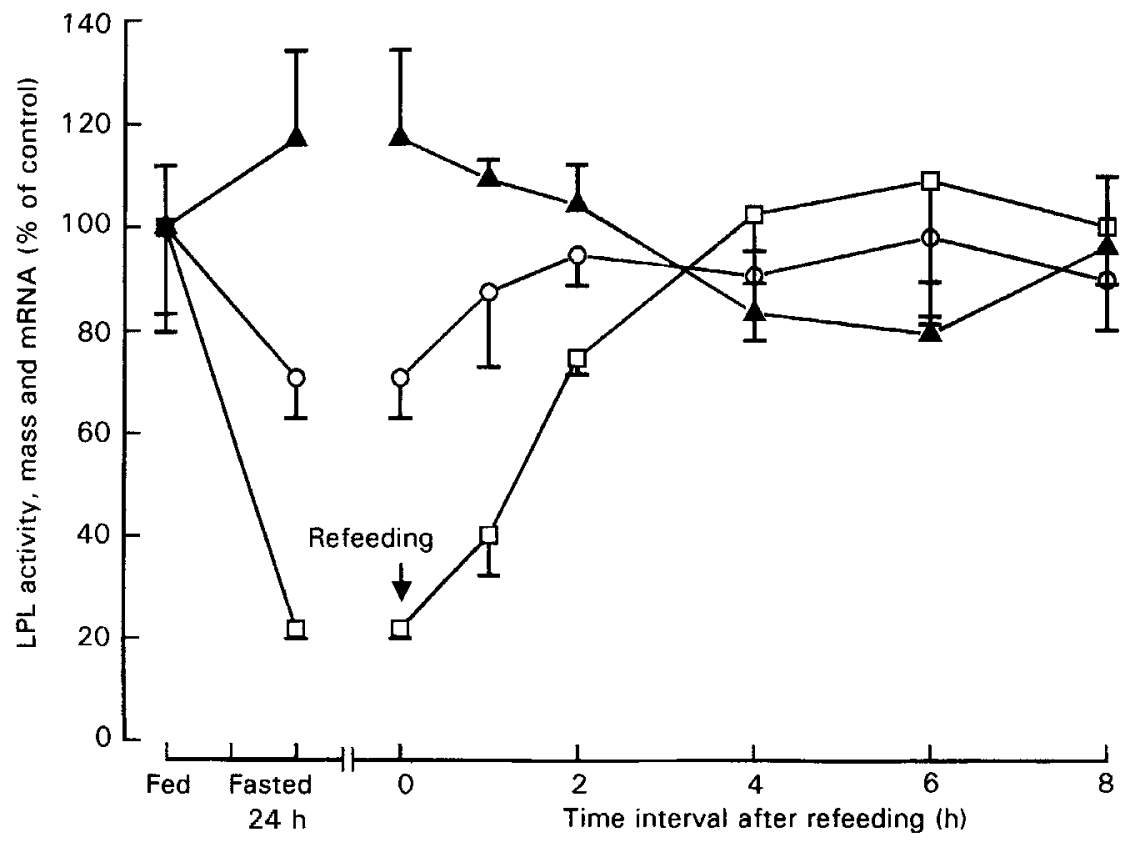

Fig. 4. Effect of re-feeding after $24 \mathrm{~h}$ of fasting. Rats were fasted for $24 \mathrm{~h}$ and re-fed ad libitum for the indicated time intervals. At each time-point, five rats were killed and pieces of epididymal adipose tissue were taken for assay of lipoprotein lipase (EC 3.1.1.34; LPL) activity ( $\square$ ), LPL mass $(O)$ and LPL mRNA ( $\Delta$ ). Values are means with their standard errors, represented by vertical bars, for five rats. (From Bergö et al. 1996a.) 
Our results confirm earlier reports that LPL in adipose tissue is regulated by both transcriptional (Raynolds et al. 1990) and post-transcriptional (Doolittle et al. 1990) mechanisms and demonstrate that the responses to long- and short-term fasting differ. The aspect we emphasize is that there is a mechanism to down-regulate adipose LPL in response to fasting. What do we know about this mechanism? When tissue extracts are separated on heparin-Sepharose, two peaks of LPL protein are obtained. One elutes at about $1 \mathrm{M}-\mathrm{NaCl}$ and is the active enzyme. Another peak elutes earlier in the gradient and has no catalytic activity. In adipose tissue from fed rats, most of the enzyme is in the active form, but in fasted rats most is in the inactive form (Bergö et al. 1996b). The specific activity of the active form is the same in the two states, the difference is that more of the enzyme is in the inactive form in the fasted state. In tissues other than the adipose tissue, the ratio active : inactive forms stays relatively constant during feeding-fasting cycles and is similar to the value found in adipose tissue in the fed state. This leads us to suggest that the default pathway for LPL synthesis leads to the active form and that in the adipose tissue there is a mechanism, switched on during fasting, that diverts most of the enzyme into an inactive state.

Why is such a mechanism needed in the adipose tissue and what metabolic consequences would come from desensitizing it? One clue to this comes from data from Frayn et al. (1995). By measuring arterio-venous differences across adipose tissue they show that three phases can be distinguished in the response of adipose tissue to a meal after fasting. Almost immediately after the meal, the net release of FFA and glycerol drops. This is an effect of insulin on intracellular lipolysis of adipose triacylglycerols by hormonesensitive lipase (EC 3.1.1.3). In this phase there is little net utilization of plasma triacylglycerol by the tissue, presumably because functional LPL activity is low. Then follows a phase of increasing utilization of plasma triacylglycerol by the tissue, but most of the triacylglycerol-fatty acids are released into the blood as FFA for use in other tissues. This would correspond to the return of LPL toward the 'fed' level. Finally, after large meals there is a phase with net deposition of triacylglycerols in the adipose tissue. Hence, it may be important for overall energy metabolism that fatty acids are diverted to other tissues during fasting, after smaller meals, and during the first few hours after larger meals.

In summary, for lipoprotein catabolism it is necessary that the triacylglycerols are split by LPL. For most tissues it is not critical where this occurs; the fatty acids can be immediately taken up or redistributed via the FFA pool. In adipose tissue there is an elaborate set of mechanisms to regulate LPL activity and lipid deposition. This is logical; adipose tissue is the expandable site for fatty acids and it is here that lipid transport must be regulated by outside factors in the interest of overall energy homeostasis.

\section{REFERENCES}

Bergö, M., Olivecrona, G. \& Olivecrona, T. (1996a). Diurnal rhythms and effects of fasting and re-feeding on rat adipose tissue lipoprotein lipase. American Journal of Physiology 271, E1092- E1097.

Bergö, M., Olivecrona, G. \& Olivecrona, T. (1996b). Forms of lipoprotein lipase in rat tissues: In adipose tissue the proportion of inactive lipase increases on fasting. Biochemical Journal 313, 893-898.

Bragdon, J. H. \& Gordon, R. S. (1958). Tissue distribution of $\mathrm{C}^{14}$ after the intravenous injection of labeled chylomicrons and unesterified fatty acids in the rat. Journal of Clinical Investigation 37, 574-578.

Brunzell, J. D. (1995). Familial lipoprotein lipase deficiency and other causes of the chylomicronemia syndrome. In Metabolic Basis of Inherited Disease, pp. 1913-1932 [C. R. Scriver, A. L. Beaudet, W. S. Sly and D. Valle, editors]. New York: McGraw-Hill Book Co.

Cryer, A., Riley, S. E., Williams, E. R. \& Robinson, D. S. (1976). Effect of nutritional status on rat adipose tissue, muscle and post-heparin plasma clearing factor lipase activities: their relationship to triglyceride fatty acid uptake by fat-cells and to plasma insulin concentrations. Clinical Science and Molecular Medicine 50, 213-221. 
Doolittle, M. H., Ben-Zeev, O., Elovson, J., Martin, D. \& Kirchgessner, T. G. (1990). The response of lipoprotein lipase to feeding and fasting. Evidence for posttranslational regulation. Journal of Biological Chemistry 265, 4570-4577.

Frayn, K. N., Coppack, S. W., Fielding, B. A. \& Humphreys, S. M. (1995). Coordinated regulation of hormonesensitive lipase and lipoprotein lipase in human adipose tissue in vivo: Implications for the control of fat storage and fat mobilization. Advances in Enzyme Regulation 35, 163-178.

Harris, K. L. \& Harris, P. A. (1973). Kinetics of chylomicron triglyceride removal from plasma in rats: Effect of dose on the volume of distribution. Biochimica et Biophysica Acta 326, 12-16.

Hultin, M., Savonen, R. \& Olivecrona, T. (1996). Chylomicron metabolism in rats: Lipolysis, recirculation of triglyceride-derived fatty acids in plasma FFA, and fate of core lipids as analyzed by compartmental modelling. Journal of Lipid Research 37, 1022-1036.

Karpe, F. \& Hultin, M. (1995). Endogenous triglyceride-rich lipoproteins accumulate in rat plasma when competing with a chylomicron-like triglyceride emulsion for a common lipolytic pathway. Journal of Lipid Research 36, 1557-1566.

Levak-Frank, S., Radner, H., Walsh, A., Stollberger, R., Knipping, G., Hoefler, G., Sattler, W., Weinstock, P. H., Breslow, J. L. \& Zechner, R. (1995). Muscle-specific overexpression of lipoprotein lipase causes a severe myopathy characterized by proliferation of mitochondria and peroxisomes in transgenic mice. Journal of Clinical Investigation 96, 976-986.

Olivecrona, G. \& Olivecrona, T. (1995). Triglyceride lipases and atherosclerosis. Current Opinion in Lipidology 6, 291-305.

Raynolds, M. V., Awald, P. D., Gordon, D. F., Gutierrez-Hartmann, A., Rule, D. C., Wood, W. M. \& Eckel, R. H. (1990). Lipoprotein lipase gene expression in rat adipocytes is regulated by isoproterenol and insulin through different mechanisms. Molecular Endocrinology 4, 1416-1422.

Samra, J. S., Clark, M. L., Humphreys, S. M., Macdonald, I. A. \& Frayn, K. N. (1996). Regulation of lipid metabolism in adipose tissue during early starvation. American Journal of Physiology 271, E541-E546. 